\title{
Profile of macular ganglion cell-inner plexiform layer thickness in healthy 6.5 year- old Swedish children
}

\author{
Urszula Arnljots $^{1 *}$, Maria Nilsson², Ida Hed Myrberg ${ }^{3}$, Ulrika Åden $^{3}$ and Kerstin Hellgren ${ }^{1}$
}

\begin{abstract}
Background: The purpose was to study the macular ganglion cell- inner plexiform layer (GC-IPL) thickness in healthy 6.5 year- old Swedish children using Optical Coherence Tomography (OCT) and to study topography symmetry within eyes and between eye pairs.
\end{abstract}

Methods: A total of 181 eyes of 92 healthy children (39 girls, 53 boys) aged 6.5 and serving as a term-born control group in the Extremely Preterm Infants in Sweden Study (EXPRESS), were examined with Cirrus HD-OCT. Main outcome measures were average and minimum values of GC-IPL thickness of the device's predefined macular sectors. Single sectors, combined sectors defined as superior and inferior hemispheres and temporal and nasal sectors were evaluated. Intra-individual GC-IPL thickness between eye pairs was analyzed. Visual acuity, refraction and general cognition were assessed and correlated to GC-IPL outcome.

Results: Eighty-five children completed the OCT examination and 155 out of 181 scans (86\%) were analyzed. The mean average GC-IPL thickness was $85.9 \mu \mathrm{m}$ ( \pm 5.3; 5th and 95th percentiles were 76.0 and $94.6 \mu \mathrm{m})$. The mean minimum GC-IPL thickness was $83.6 \mu \mathrm{m}( \pm 4.9 ; 5$ th and 95th percentiles were 75.4 and $92.3 \mu \mathrm{m})$. The difference in thickness between nasal and temporal sectors and between superior and inferior hemisphere sectors were less than $2 \mu \mathrm{m}$. The difference between average GC-IPL thickness and minimum GC-IPL thickness was $2.3 \mu \mathrm{m}( \pm 1.9 ; 5$ th and 95th percentiles were 0.0 and $6.0 \mu \mathrm{m})$. The difference between the thickest and thinnest sector within eye was $6.4 \mu \mathrm{m}( \pm 2.2 ;$ th and 95th percentiles were 3.0 and $10.0 \mu \mathrm{m})$. There was a moderate correlation in the difference between the nasal combined and the temporal combined sectors within eye pairs $(p<0.0001$, Spearman's $\rho 0.58)$. The average GC-IPL thickness was weakly positively correlated with SE (spherical equivalent; combined sphere and $1 / 2$ cylinder) ( $p=0.031$, Spearman's $\rho$ 0.23).

Conclusions: This study provides normative GC-IPL thickness values for healthy 6.5 year- old Swedish children. The GC-IPL thickness variations within eyes and within eye pairs are generally small. It could therefore be assumed that larger variations are sensitive markers of focal GC-IPL thinning due to damage to the primary visual pathways in children.

Keywords: Optical coherence tomography (OCT), Children, Ganglion cell-inner Plexiform layer (GC-IPL), Normal values, Inter and intraocular symmetry

\footnotetext{
* Correspondence: urszula.arnljots@ki.se

${ }^{1}$ Department of Clinical Neuroscience, Karolinska Institutet, Stockholm, Sweden

Full list of author information is available at the end of the article
}

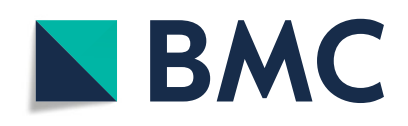

(c) The Author(s). 2020 Open Access This article is licensed under a Creative Commons Attribution 4.0 International License, which permits use, sharing, adaptation, distribution and reproduction in any medium or format, as long as you give appropriate credit to the original author(s) and the source, provide a link to the Creative Commons licence, and indicate if changes were made. The images or other third party material in this article are included in the article's Creative Commons licence, unless indicated otherwise in a credit line to the material. If material is not included in the article's Creative Commons licence and your intended use is not permitted by statutory regulation or exceeds the permitted use, you will need to obtain permission directly from the copyright holder. To view a copy of this licence, visit http://creativecommons.org/licenses/by/4.0/. The Creative Commons Public Domain Dedication waiver (http://creativecommons.org/publicdomain/zero/1.0/) applies to the data made available in this article, unless otherwise stated in a credit line to the data. 


\section{Background}

Optical coherence tomography (OCT) is a non-invasive and objective imaging technique that provides crosssectional images of the retinal layers and the optic nerve [1]. Since OCT came into clinical use it has undergone several improvements. The newer, spectral domain technology (SD-OCT) offers three-dimensional, high-speed retinal imaging and thereby enables high resolution imaging less sensitive to eye movements than time domain technology-based OCT [2, 3]. Moreover, advances in segmentation algorithms have permitted measurement of individual retinal layers in the macular region [4]. The macular ganglion cell + inner plexiform layer (GC-IPL) has proven to be of interest in detection and follow-up of for instance in glaucoma $[5,6]$ and other optic nerve diseases: optic pathway glioma [7, 8], compressive optic neuropathies [9] and hereditary neuropathies [10, 11]. Although the reliability and repeatability have been proven to be satisfying when examining children with Cirrus SD-OCT [12] the GC-IPL parameter has not been extensively investigated for younger age groups and there is no normative database. Instead the peripapillary retinal nerve fiber layer (pRNFL) parameter has been more widely explored.

In children pRNFL thickness can be useful for detection and monitoring of glaucoma, optic nerve hypoplasia, optic neuritis and in the differential diagnosis of optic nerve swelling: elevation secondary to increased intracranial pressure (i.e., papilledema) or due to other congenital/structural anomalies (i.e., pseudopapilledema) [13-15]. Possible advantages of replacing or adding GCIPL to pRNFL measurements are that loss of axons at the optic nerve head could be masked by swelling at an early stage. Fewer vessels in the macular region compared to the optic nerve head leads to better repeatability between measures and a reduction of artifacts [16]. Furthermore, damage to the post-geniculate visual pathway has been associated with focal GC-IPL thinning caused by retrograde trans-synaptic degeneration (RTSD) [17, 18]. These studies have also shown that GC-IPL topography predicts visual field defects more directly compared to pRNFL. Only a few previous studies report reference values for GC-IPL thickness in children [19-22]. These studies also varied in methodology and epidemiology.

\section{Methods}

The purpose of the present study was to describe the intra- and inter ocular GC-IPL layer topography to determine normative data on thickness variations within and between eyes. This information may improve the preconditions for early identification of focal GC-IPL thinning caused by pathology affecting the primary visual pathway.

\section{Study population}

The group of children aged 6.5 years $(n=94)$, was drawn from the Swedish Medical Birth Register and was serving as a term-born control group in a prospective follow-up study of Extremely Preterm Infants in Sweden Study (EXPRESS) as previously described [23, 24]. Included in the study were subjects born at term (gestational age; GA $\geq 37$ weeks), at normal birthweights ( $\geq 2500$ g), born in Stockholm County and with no systemic diseases.

\section{Methods/procedures \\ Optical coherence tomography}

The OCT scans were performed by two examiners through undilated pupils using the Cirrus HD-OCT device (Cirrus; Carl Zeiss Meditec, Dublin, CA). Macular Cube $512 \times 128$ scan protocol and automated GC-IPL analysis segmentation algorithm, incorporated into the Cirrus 6.0 software were selected.

The main outcome measures for GC-IPL thickness per eye were Average and Minimum GC-IPL (lowest GC-IPL thickness over a single meridian crossing the annulus), individual sectors (superotemporal $[S T]$, superior $[S]$, superonasal [SN], inferonasal [IN], inferior [I], inferotemporal [IT]]), as well as Thickest and Thinnest individual sectors. In addition, we analyzed combined sector thicknesses defined as superior $(\mathrm{SH} ; \mathrm{ST}+\mathrm{S}+\mathrm{SN})$ and inferior hemispheres $(\mathrm{IH}$; $\mathrm{IN}+\mathrm{I}+\mathrm{IT})$ and temporal $(\mathrm{T} ; \mathrm{ST}+\mathrm{IT})$ as well as nasal $(\mathrm{N}$; $\mathrm{SN}+\mathrm{IN}$ ) sectors (Fig. 1) [25].

The intraocular GC-IPL topography was further analyzed by subtracting Average with Minimum GC-IPL; Thickest with Thinnest individual sectors; $\mathrm{N}$ with $\mathrm{T}$ sectors and finally $\mathrm{SH}$ with $\mathrm{IH}$. The scans were reviewed by two independent examiners ( $\mathrm{MN}$ and $\mathrm{UA}$ ) and those with signal strength $<6$ were excluded. Further, a thorough evaluation of the remaining scans revealed a recognizable pattern of artifacts yielding segmentation errors in some of them, due to unstable fixation [26]. Those artifacts included a so-called double fovea resulting in false thinning of the GC-IPL inferior sectors [27] or false thickening of the superior sectors. Double fovea occurred due to a transient microsaccade looking upward (rotating the fovea downward into the path of the raster scan) followed by re-fixation onto the central marker. The scans with artifacts as described as above, defined as Uncomplete Scans, were not included in the final analysis. The Uncomplete Scans were compared with the scans without artifacts, defined as Complete Scans, in order to study if artifacts tend to give any general pattern/thickness deviations on group level.

A. The six macular sectors: $S=$ superior, $S N=$ superonasal, IN = inferonasal, $I=$ inferior,$\quad I T=$ inferotemporal, ST=superotemporal. B. The temporal (T) and nasal (N) sectors. C. The superior (SH) and inferior hemisphere (IH). 


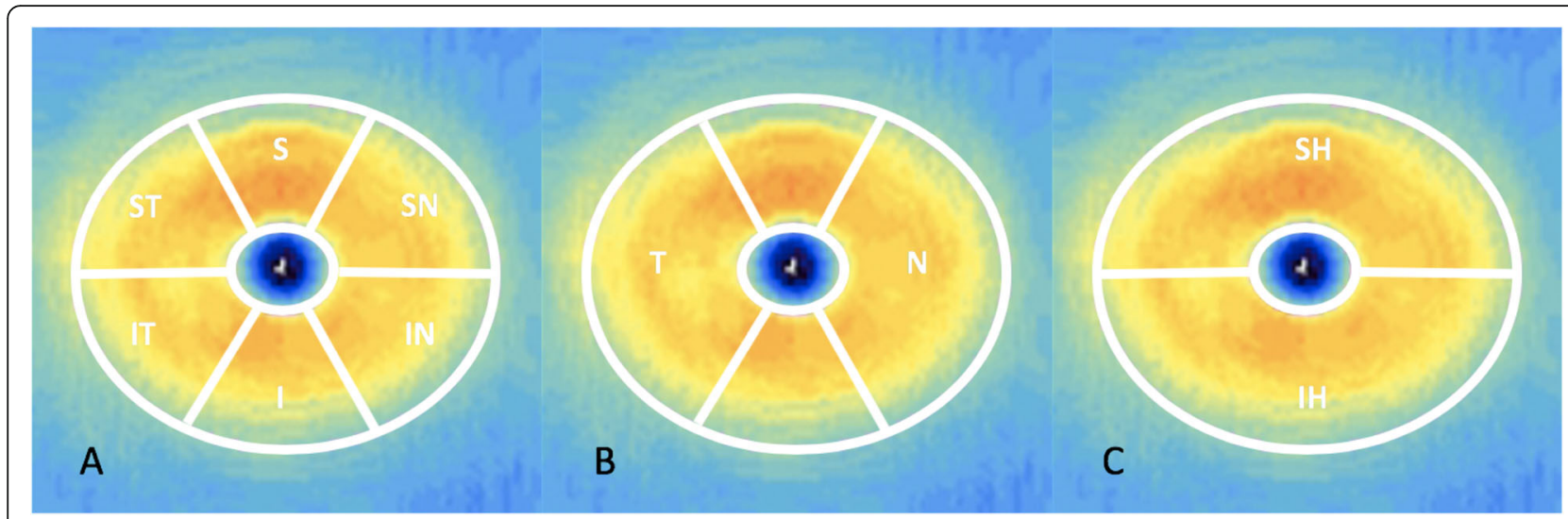

Fig. 1 OCT image of the macula with the elliptic annulus (dimensions around the fovea)

\section{Ophthalmologic assessments}

Refraction was assessed with autorefractor of eyes under cycloplegia (mixture of phenylephrine 1.5\% and cyclopentolate $0.85 \%$ ). Visual acuity (VA) was evaluated monocularly, with habitual correction using Lea Hyvärinen symbols charts assessed at a distance of $3 \mathrm{~m}$ [28]. The data was presented in Snellen. Stereoacuity was measured by using TNO test.

\section{Cognitive assessments}

The Swedish version of Wechsler Intelligence Scale for Children-Fourth Edition (WISC-IV) was used in order to assess the cognitive ability [29]. The full-scale intelligence quotient was taken as a measure of general cognition.

Written informed consent was obtained from each subject's parent or legal guardian. The study was approved by the Regional Ethical Review Board in Stockholm and conducted in accordance with the tenets of the Declaration of Helsinki.

\section{Statistical analysis}

Both eyes from each patient were used for analysis. Descriptive statistics are presented as means, standard deviations and 95\% confidence intervals for continuous variables, and frequencies and percentages, for categorical variables. Mean GC-IPL and 95\% confidence intervals for each sector were estimated using Linear Mixed Models, with a random intercept per child, taking into account dependencies within eye pairs and between included and excluded eyes of the same child. Gender differences in mean GC-IPL were tested using Linear Mixed Models, with a random intercept per child. The GC-IPL distribution synchronicity within eye pairs was conducted with a correlation analysis between the right and left eye regarding the differences between $\mathrm{N}$ and $\mathrm{T}$ sectors as well as between $\mathrm{SH}$ and $\mathrm{IH}$. Correlations between macula parameters and continuous variables (refraction, VA, birth weight, IQ) were calculated using Spearman's Rank Correlation Coefficient, with cluster robust standard errors, taking into account dependencies within eye pairs. Pearson correlation was used to estimate correlation in the difference between $\mathrm{SH}$ and $\mathrm{IH}$, and $\mathrm{N}$ and $\mathrm{T}$, respectively, between left and right eyes within the same child. All statistical analyses were performed using $\mathrm{R}$ version 3.6.0.

\section{Results}

Nighty-four children were invited to participate in the study. Two children were excluded due to missing data. In one case, a boy, imaging could not be performed due to technical problems, and in another case due to lack of cooperation. Hence, 181 eyes of 92 children (39 girls, 53 boys) completed the OCT examination. In 155 of these 181 (86\%) OCT images, provided by 85 children there were Complete Scans (without artifacts) and in 26 (14\%) out of 181 OCT images there were Uncomplete Scans (with artifacts). Clinical data of the 85 participants are presented in Table 1. All but one child had $\mathrm{TNO}<120 \mathrm{~s}$ of arch.

Table 1 Clinical data of 85 study participants

\begin{tabular}{lll}
\hline & Mean (SD) & Range \\
\hline Gestational age (weeks) & $40.1(1.2)$ & $37-42$ \\
Birth weight (g) & $3649.6(430.7)$ & $2850-4720$ \\
IQ score & $105.2(10.7)$ & $85-130$ \\
LogMAR VA RE & $0.015(0.09)$ & $-0.1-0.4$ \\
LogMAR VA LE & $0.004(0.075)$ & $-0.2-0.2$ \\
Snellen VA RE & $20 / 20(20 / 100)$ & $20 / 50-20 / 16$ \\
Snellen VA LE & $20 / 20(20 / 100)$ & $20 / 32-20 / 12.5$ \\
SE RE (D) & $1.4(1.0)$ & $-1-+6.12$ \\
SE LE (D) & $1.4(0.8)$ & $-0.125-+6.25$ \\
\hline
\end{tabular}

LE Left eye, $R E$ Right eye, $S E$ Spherical equivalent, $S D$ Standard deviation, $V A$ Visual acuity (with habitual correction). 
The GC-IPL measurements and intraocular GC-IPL topography

The GC-IPL measurements, as well as the topography as predefined intraocular sector differences of 155 eyes are presented in Table 2. The mean average GC-IPL was 85.9 $( \pm 5.4 \mu \mathrm{m})$, the 5 th and the 95th percentiles were 76.0 and $94.6 \mu \mathrm{m}$. The mean minimum GC-IPL was 83.6 ( \pm $4.9 \mu \mathrm{m})$, the 5th and the 95th percentiles were 75.4 and $92.3 \mu \mathrm{m}$. The mean absolute difference between the Thickest and Thinnest sector was $6.4 \pm 2.2$, between the two hemispheres $\mathrm{SH}$ and $\mathrm{IH}$ (both directions) was $0.1 \pm$ 2.0, between combined sectors $\mathrm{N}$ and $\mathrm{T}$ (both directions) was $1.2 \pm 2.5 \mu \mathrm{m}$. For details of the distribution of GC-IPL measurements and intraocular differences, see Fig. 2.

The profile of GC-IPL thickness in the six macular sectors is presented in Fig. 3a and in comparison to other studies in pediatric and adult populations in Fig. 3b.

\section{The GC-IPL distribution symmetry within eye pairs}

Of the 85 children with Complete Scans, 70 provided scans of both eyes, enabling analyses of symmetry within eye pairs. The inter-ocular difference in average GC-IPL thickness was $1.5(1.3,0-6 \mu \mathrm{m})$. It was more common to have a thicker $\mathrm{SH}$ than $\mathrm{IH}$, and $\mathrm{N}$ than $\mathrm{T}$. There was a weak but statistically significant correlation in the difference between $\mathrm{SH}$ and $\mathrm{IH}$ within eye pairs $(p=0.016$, Spearman's $\rho$ 0.29). There was a moderate correlation in the difference between $\mathrm{N}$ and $\mathrm{T}$ within eye pairs $(p<$ 0.0001, Spearman's $\rho$ 0.58), for details see Fig. 4.

\section{Correlations between GC-IPL and clinical outcome}

There was no statistically significant difference in average and minimum GC-IPL thickness between males and females $(p=0.30, p=0.24$, respectively). The average GC-IPL thickness was weakly positively correlated with SE $(p=0.031$, Spearman's $\rho 0.23)$. There was no statistically significant correlation between average GC-IPL and birth weight, IQ or VA at 6.5 years $(p>0.05)$.

\section{Uncomplete OCT scans compared to complete scans}

On average, the 26 images with Uncomplete Scans had thicker superior sectors than the 155 Complete Scans.

Table 2 Macular GC-IPL thicknesses in micrometers in all eyes with Complete Scans of OCT ( $n=155$ of 85 children)

\begin{tabular}{|c|c|c|c|c|c|c|}
\hline & \multirow{2}{*}{$\begin{array}{l}\text { Mean (SD; range) } \\
\text { in } \mu \mathrm{m}\end{array}$} & \multirow{2}{*}{$\begin{array}{l}95 \% \mathrm{Cl} \text { for the } \\
\text { mean in } \mu \mathrm{m}\end{array}$} & \multicolumn{4}{|c|}{ Percentile in $\mu \mathrm{m}$} \\
\hline & & & $5 \%$ & $10 \%$ & $90 \%$ & $95 \%$ \\
\hline \multicolumn{7}{|l|}{ AREA AND SECTOR THICKNESSES } \\
\hline Average GC-IPL Thickness ( $\mu \mathrm{m})$ & $85.9(5.3 ; 70-98)$ & $(84.7-87.0)$ & 76.0 & 79.0 & 93.0 & 94.6 \\
\hline Minimum GC-IPL Thickness $(\mu \mathrm{m})$ & $83.6(4.9 ; 70-95)$ & $(82.6-84.7)$ & 75.4 & 77.0 & 90.0 & 92.3 \\
\hline \multicolumn{7}{|l|}{ Singel sectors } \\
\hline ST & $84.5(5.6 ; 70-101)$ & $(83.3-85.7)$ & 75.0 & 77.0 & 91.0 & 94.0 \\
\hline S & $86.1(6.2 ; 71-103)$ & $(84.8-87.5)$ & 74.0 & 78.4 & 94.0 & 97.0 \\
\hline SN & $87.1(5.8 ; 72-103)$ & $(85.9-88.4)$ & 76.0 & 79.4 & 94.0 & 96.0 \\
\hline IN & $86.1(5.5 ; 68-99)$ & $(84.9-87.3)$ & 76.0 & 80.0 & 93.0 & 95.0 \\
\hline । & $85.1(5.5 ; 68-101)$ & $(83.9-86.3)$ & 76.0 & 78.0 & 92.0 & 94.0 \\
\hline IT & $86.3(5.4 ; 71-105)$ & $(85.2-87.5)$ & 77.0 & 79.4 & 93.0 & 96.0 \\
\hline \multicolumn{7}{|l|}{ Combined sectors } \\
\hline $\mathrm{SH}$ & $85.9(5.7 ; 71-100.3)$ & $(84.7-87.1)$ & 75.1 & 78.6 & 92.7 & 95.9 \\
\hline $\mathbb{H}$ & $85.8(5.2 ; 69.7-98)$ & $(84.7-86.9)$ & 76.5 & 79.6 & 92.2 & 95.0 \\
\hline $\mathrm{N}$ & $86.6(5.5 ; 71-100)$ & $(85.4-87.8)$ & 75.8 & 80.2 & 93.3 & 95.6 \\
\hline $\mathrm{T}$ & $85.4(5.4 ; 70.5-103)$ & $(84.2-86.6)$ & 76.3 & 78.7 & 92.3 & 94.1 \\
\hline \multicolumn{7}{|l|}{ Selected Single Sectors } \\
\hline Thickest Sector & $89.1(5.8 ; 72-105)$ & $(87.8-90.3)$ & 78.4 & 82.0 & 96.0 & 99.3 \\
\hline Thinnest Sector & $82.6(5.2 ; 68-95)$ & $(81.5-83.7)$ & 73.0 & 76.0 & 90.0 & 91.0 \\
\hline \multicolumn{7}{|l|}{ INTRAOCULAR SYMMETRIES } \\
\hline Difference between Average and Minimum & $2.3(1.9 ;-1-12)$ & $(1.85-2.7)$ & 0.0 & 0.0 & 5.0 & 6.0 \\
\hline Difference between Thickest and Thinnest Sector & $6.4(2.2 ; 2-24)$ & $(5.90-7.0)$ & 3.0 & 4.0 & 9.0 & 10.0 \\
\hline Difference between $\mathrm{SH}$ and $\mathrm{IH}$ & $0.1(2.0 ;-6.33-13.67)$ & $(-0.40-0.6)$ & -3.77 & -2.67 & 3.20 & 4.0 \\
\hline Difference between $\mathrm{N}$ and T Sectors & $1.2(2.5 ;-8-8)$ & $(0.66-1.7)$ & -3.0 & -2.00 & 4.80 & 6.15 \\
\hline
\end{tabular}

SD Standard deviation, GC-IPL Ganglion cell inner + plexiform layer, ST Superotemporal, S Superior, SN Superonasal, IN Inferonasal, I Inferior, IT Inferotemporal, SH Superior hemisphere, $I H$ Inferior hemisphere, $T$ Temporal sectors, $N$ Nasal sectors. 

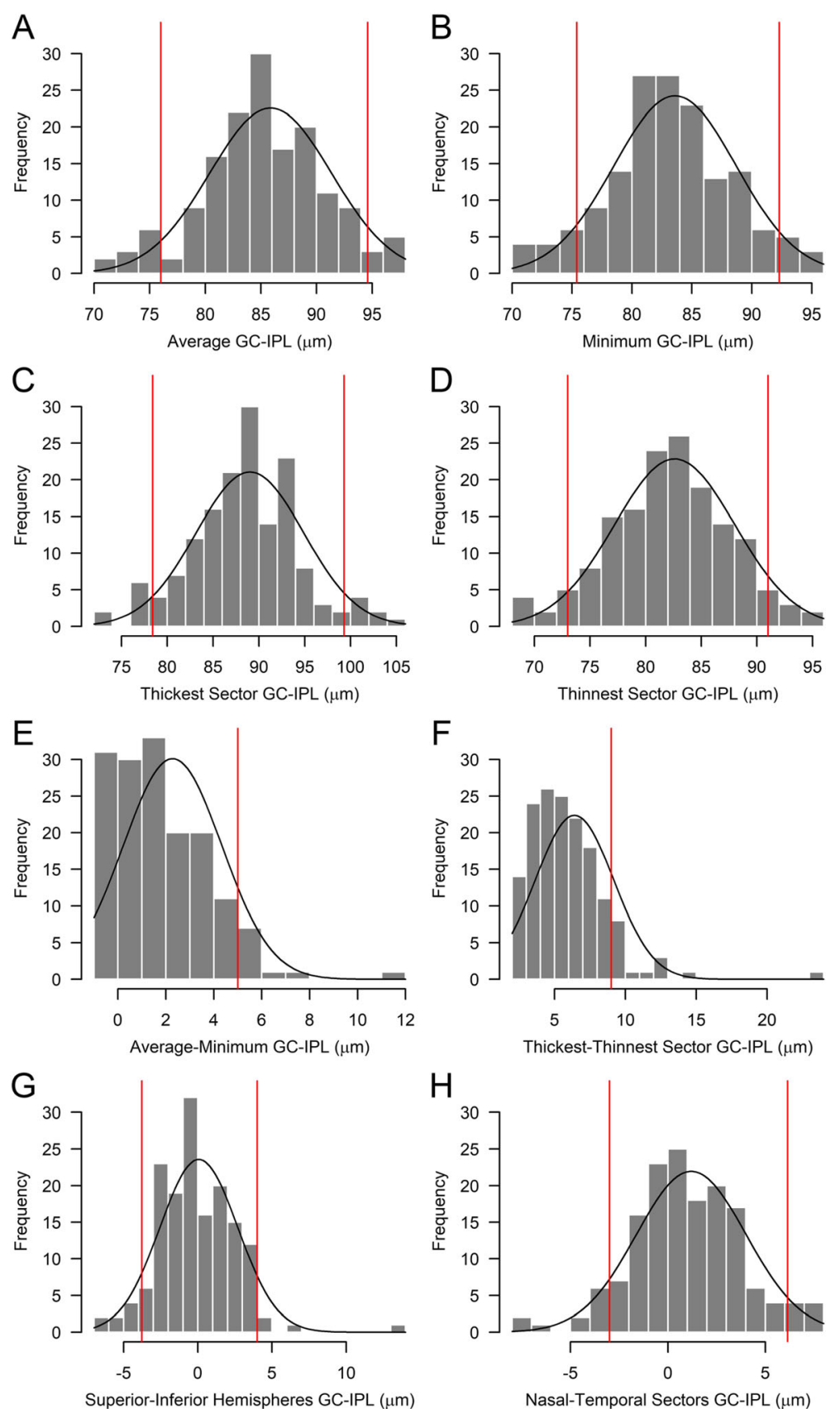

Fig. 2 Distribution of GC-IPL thickness (histograms) compared with normal distribution (solid curve) in 155 Complete Scans. a. Average overall GC-IPL thickness, b. Minimum GC-IPL thickness, c. Thickest sector GC-IPL (superior, superiotemporal, inferiotemporal, inferior, inferionasal or superionasal per eye), d. Thinnest sector GC-IPL (superior, superiotemporal, inferiotemporal, inferior, inferionasal or superionasal sector per eye). Difference in GC-IPL thickness between: e. Average and minimum, f. Thickest and thinnest sector, $\mathbf{g}$. Superior and inferior hemisphere, $\mathbf{h}$. Nasal and temporal sectorial GC-IPL. Red lines indicating 5 and 95\% percentiles (A, B, C, D, G, H) and 90\% percentile (E, F). GC-IPL $=$ Ganglion cell inner + plexiform layer

The largest difference was seen in $\mathrm{S}(5.3 \mu \mathrm{m}, 95 \% \mathrm{CI}$ $3.1-7.5, p<0.0001)$ and resulted in slightly higher average GC-IPL in the Uncomplete Scans than in the Complete Scans (mean difference $2.1 \mu \mathrm{m}$; 95\% CI 1.13.0; $p<0.0001$ ). None of the sectors were statistically significantly thinner among Uncomplete Scans in comparison to Complete Scans. Inclusion of Uncomplete Scans in the total analysis did not change the mean values of any OCT variable significantly. Figure 5 displays the average and minimum values of the a) 181 eyes from 91 children, with both Complete and Uncomplete Scans of at least one eye; b) 155 eyes from 85 children, 


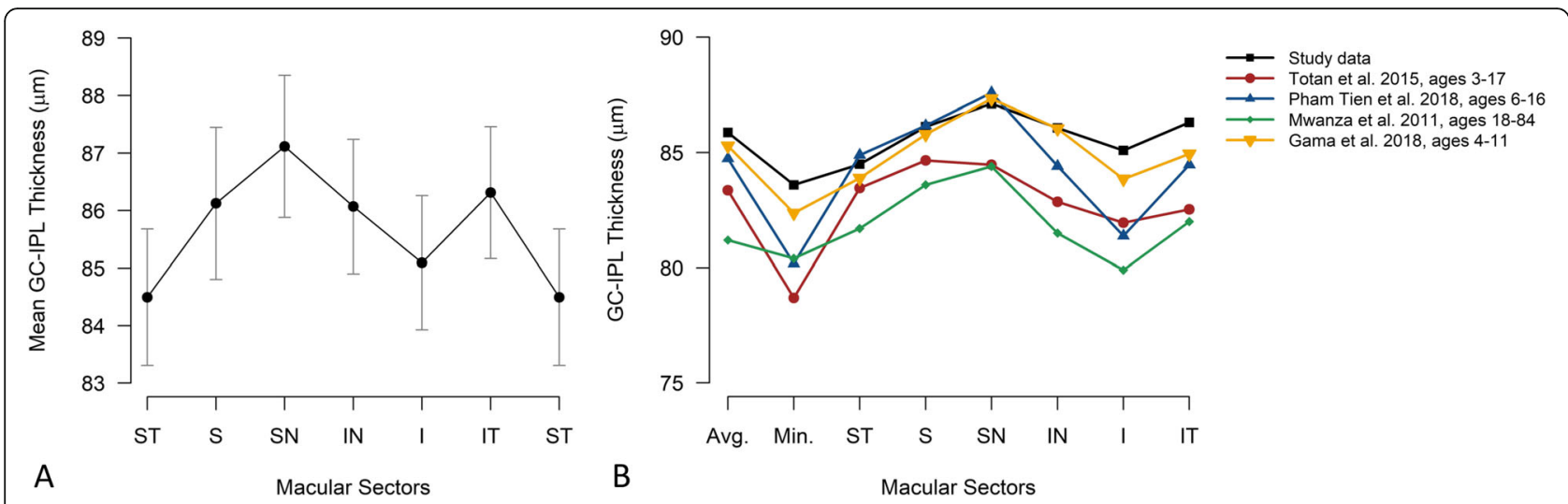

Fig. 3 Graphic profile of mean GC-IPL thickness in six macular sectors in study population (a), comparison of studies reporting OCT macular GCIPL thickness in normal pediatric population (b). Avg = Average, Min = Minimum, ST = superotemporal, $\mathrm{S}=$ superior, $\mathrm{SN}=$ superonasal, $\mathrm{IN}=$ inferonasal, I = inferior, IT = inferotemporal, GC-IPL = Ganglion cell inner + plexiform layer

with Complete Scans of at least one eye; c) 140 eyes from 70 children, with Complete Scans of both eyes.

\section{Discussion}

The average GC-IPL thickness range, distribution and mean as well as the GC-IPL distribution between sectors seen in our study group (at $6.5 \mathrm{yrs}$ ) was very similar to what other have seen in groups of children aged 3-17 [19, 20] and adults [4]. In addition, we reported the "within eye" as well as "within eye pairs" GC-IPL distribution and observed that the differences are very small within individuals i.e., normal anatomy is associated with small differences in GC-IPL thickness between sectors and between eyes in the same individual. At the same time the differences in mean thickness between individuals are quite large. Therefore, it seems as important to study thickness variations between sectors and eyes on individual level as to compare with a normative database in order to increase the possibility to detect focal ganglion cell loss at an early stage of pathology.

In this study, the superonasal sector was thickest and the superotemporal sector was thinnest, but the differences were small (Fig. 3a). The same trend was observed in other studies (Fig. 3b) with similar results on a group level [19] whereas greater differences were found by Gama et al [20] and Tien et al [22]. Clinically, the attention should be paid to thickness normal profile of macular sectors, because GC-IPL thinning may be useful in detecting neurodegenerative diseases

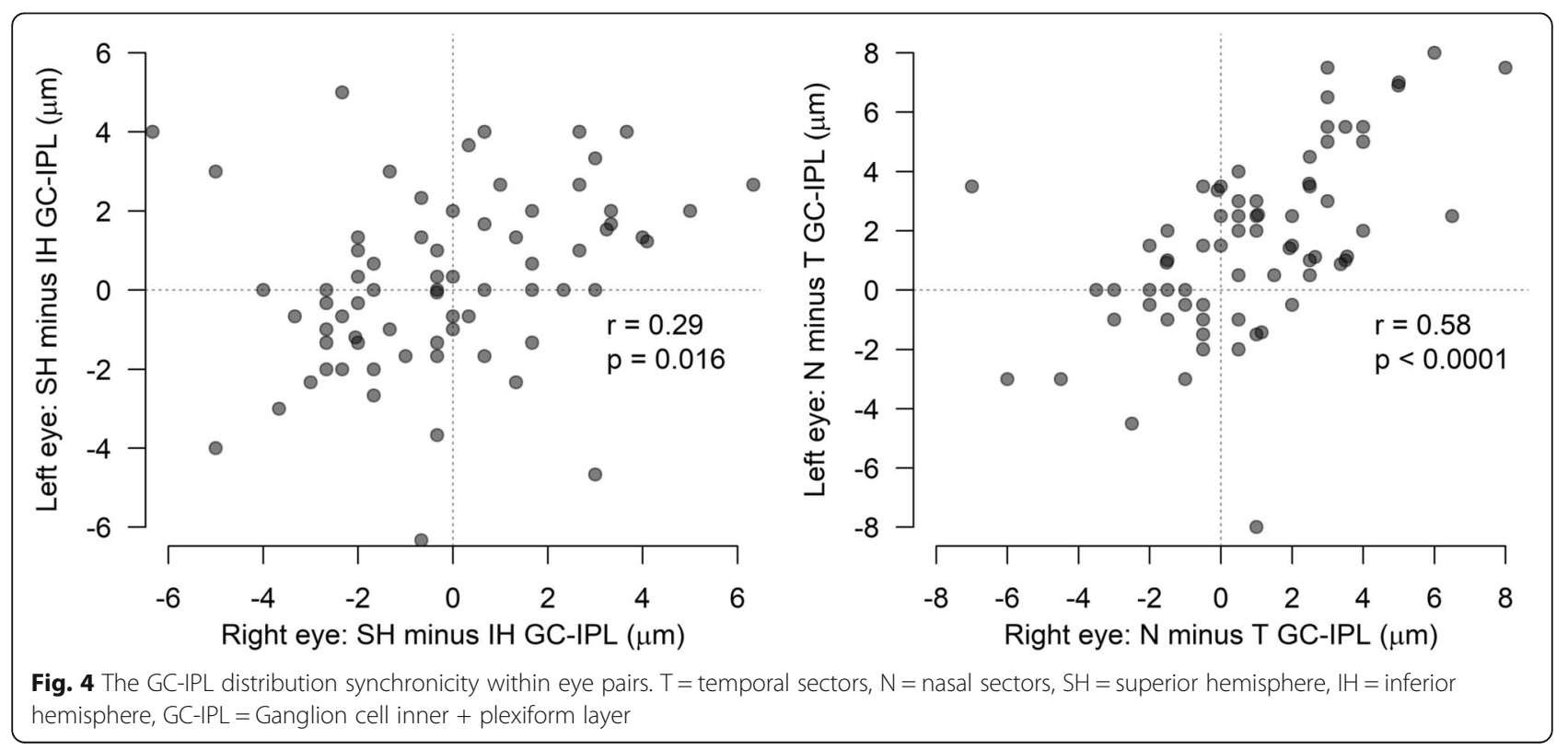




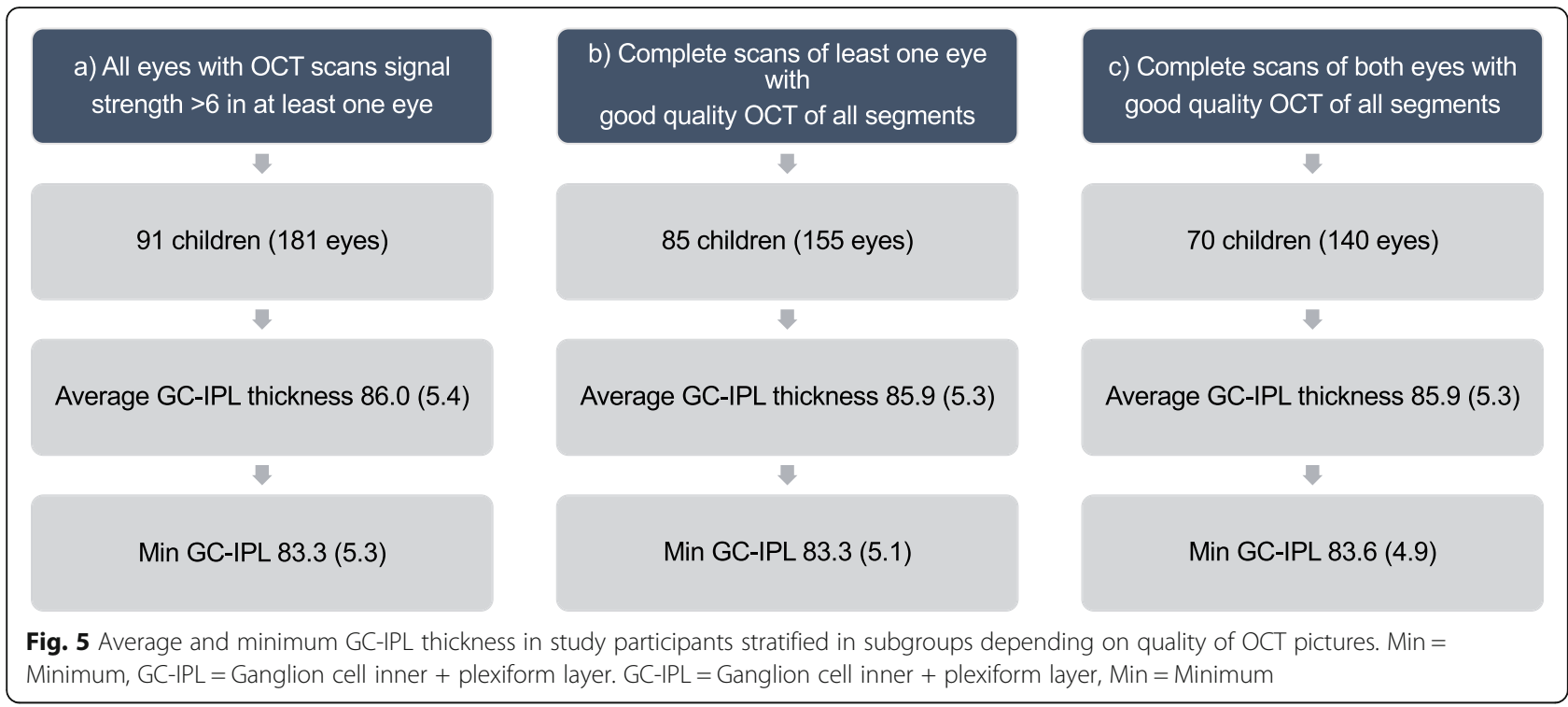

and progression [30] as well as glaucoma [5]. In addition, superior hemisphere was slightly thicker than that of the inferior, and the nasal sectors had a significantly thicker GC-IPL compered to temporal ones. This GC-IPL topography profile corresponds to Curcio and Allen's histologic study, that shows greater ganglion cell density in the nasal and superior retinal regions [31]. Interestingly, the differences in the thickness between combined sectors are very small in healthy children, thus bigger differences may implicate underlying pathology.

In this study 26 OCT scans with good signal strength but with visual artifacts owing to fixation problems were excluded. Images with gaze-artifacts/ segmentation error may mimic pathology by significant increased Average and Superior Sectors GC-IPL thickness. These scans should be checked and discarded, with the rescanning performed during the same visit. Interestingly, there was no significant decrease in minimum and inferior sectors GC-IPL thickness. In clinical follow-up of a small child, a thinning of superior GC-IPL over time may thus signify an improved fixation and not necessarily pathology. In a child with unstable fixation, it's therefore important to take into account the risk of falsely thick Superior GC-IPL sectors in the baseline scans of the first examinations.

We couldn't find an association between gender and GC-IPL thickness $(p=0.30)$ in line with Totan et al [19]. A mean increase in Average GC-IPL thickness with increasing hyperopia was found in this study. This result is comparable by other studies [21, 22, 32]. Van Koolwijk et al have previously described that cognitive functioning is associated with pRNFL thickness in healthy young individuals aged 18-39years [33]. However, RNFL only explained a small portion of the variance in cognitive functioning. In our study group, including 6.5 year-old controls, no association between IQ and GC-IPL was found and GC-IPL does not seem to be any precise predictor of cognitive ability as estimated by WISC-IV in young healthy children.

Limitation of this study that the Cirrus Ganglion Cell Analysis does not account for magnification errors during acquisition or analysis. In our study we have not studied axial length as well as intraocular pressure due to limited time of examination. Strengths of this study include the use of the new generation Cirrus SD-OCT, novel analysis including intra- and interocular measurement.

\section{Conclusions}

Normal GC-IPL topography in healthy children shows fairly large variations in average thickness between individuals. To increase sensitivity to detect pathologic GCIPL thinning we suggest to look for differences between sector within eye and between eyes on an individual level since they are very small in healthy eyes.

To detect pathologic GC-IPL loss we suggest that asymmetry is considered as well as the difference between the average sector GC-IPL thickness compared to the minimum GC-IPL thickness.

\footnotetext{
Abbreviations

Avg: Average; EXPRESS: Extremely Preterm Infants in Sweden Study; GA: Gestational age; GC-IPL: Ganglion cell + inner plexiform layer; I: Inferior; IH: Inferior hemisphere; IN: Inferonasal; IT: Inferotemporal; LE: Left eye; Min: Minimum; N: Nasal sectors; OCT: Optical coherence tomography; pRNFL: Peripapillary retinal nerve fiber layer; RE: Right eye; RTSD: Retrograde trans-synaptic degeneration; S: Superior; SD-OCT: Spectral domain technology; SD: Standard deviation; SH: Superior hemisphere; SN: Superonasal; ST: Superotemporal; T: Temporal sectors; VA: Visual acuity
} 


\section{Acknowledgments}

We would like to express our sincere thanks to the EXPRESS Group, to Lena Falkman and Jónína Hreinsdóttir for performing the ophthalmological examinations, and to Eva Eklöf for performing the psychological tests

\section{Authors' contributions}

$\mathrm{KH}, \mathrm{MN}$ and $\mathrm{U} \AA$ planned the study. $\mathrm{KH}$ and $\cup \AA$ wrote the applications to the Ethical Review Board and the Swedish National Board of Health and Social Welfare. $\mathrm{KH}$ and $\mathrm{MN}$ examined the patients. $\cup \mathrm{A}, \mathrm{KH}, \mathrm{MN}, \mathrm{IHM}, \mathrm{UA}$ did the data analyses. UA and $\mathrm{KH}$ were the main contributors in writing the manuscript, and MN, IHM, UÅ participated. All authors read and approved the final manuscript.

\section{Funding}

The study was supported by the Bernadotte Foundation For Children's Eyecare (Sigvard and Marianne Bernadotte Research Foundation for Children's Eyecare), the Stiftelsen Kronprinsessan Margaretas Arbetsnämnd för Synskadade, the Stiftelsen Sven Jerrings Fond, the Swedish Society of Medicine, the Stockholm County Council, and the Karolinska Institutet. The funding organizations had no role in the design or conduct of this research. Open access funding provided by Karolinska Institute.

\section{Availability of data and materials}

The datasets analyzed during the current study are available from the corresponding author on reasonable request.

\section{Ethics approval and consent to participate}

All procedures in the study were in accordance with the ethical standards of the institutional and/or national research committee and the 1964 Helsinki declaration and its later amendments or comparable ethical standards. The study was approved by the Regional Ethical Review Board in Stockholm, Sweden (number: 2010/850-31/1). Inform written consent for participating was obtained from caregivers to the individual participants included in the study.

\section{Consent for publication}

Not applicable. No individual data, details or images occur in the manuscript.

\section{Competing interests}

The authors declare that they have no competing interests.

\section{Author details}

'Department of Clinical Neuroscience, Karolinska Institutet, Stockholm, Sweden. ${ }^{2}$ Department of Clinical Neuroscience, Unit of Optometry, Karolinska Institutet, Stockholm, Sweden. ${ }^{3}$ Department of Women's and Children's Health, Karolinska Institutet, Stockholm, Sweden.

\section{Received: 6 March 2020 Accepted: 6 August 2020}

\section{Published online: 12 August 2020}

\section{References}

1. Huang D, Swanson EA, Lin CP, Schuman JS, Stinson WG, Chang W, et al. Optical coherence tomography. Science. 1991;254(5035):1178-81.

2. Leung CK-S, Cheung CY-L, Weinreb RN, Qiu Q, Liu S, Li H, et al. Retinal nerve fiber layer imaging with spectral-domain optical coherence tomography: a variability and diagnostic performance study. Ophthalmology. 2009:116(7):1257-63.e12632.

3. Leite MT, Rao HL, Weinreb RN, Zangwill LM, Bowd C, Sample PA, et al. Agreement among spectral-domain optical coherence tomography instruments for assessing retinal nerve fiber layer thickness. Am J Ophthalmol. 2011:151(1):85-92.e1.

4. Mwanza JC, Durbin MK, Budenz DL, Girkin CA, Leung CK, Liebmann JM, et al. Profile and predictors of normal ganglion cell-inner plexiform layer thickness measured with frequency-domain optical coherence tomography. Invest Ophthalmol Vis Sci. 2011;52(11):7872-9.

5. Mwanza JC, Oakley JD, Budenz DL, Chang RT, Knight OJ, Feuer WJ. Macular ganglion cell-inner plexiform layer: automated detection and thickness reproducibility with spectral domain-optical coherence tomography in glaucoma. Invest Ophthalmol Vis Sci. 2011;52(11):8323-9.
6. Schuman JS, Hee MR, Puliafito CA, Wong C, Pedut-Kloizman T, Lin CP, et al. Quantification of nerve fiber layer thickness in normal and glaucomatous eyes using optical coherence tomography. Arch Ophthalmol. 1995;113(5): 586-96.

7. Avery RA, Cnaan A, Schuman JS, Trimboli-Heidler C, Chen C-L, Packer RJ, et al. Longitudinal Change of Circumpapillary Retinal Nerve Fiber Layer Thickness in Children With Optic Pathway Gliomas. Am J Ophthalmol. 2015; 160(5):944-52.e1.

8. Gu S, Glaug N, Cnaan A, Packer RJ, Avery RA. Ganglion cell layer-inner plexiform layer thickness and vision loss in young children with optic pathway gliomas. Invest Ophthalmol Vis Sci. 2014;55(3):1402-8.

9. Lee EJ, Yang HK, Kim TW, Hwang JM, Kim YH, Kim CY. Comparison of the pattern of retinal ganglion cell damage between patients with compressive and glaucomatous optic neuropathies. Invest Ophthalmol Vis Sci. 2015; 56(12):7012-20.

10. Balducci N, Savini G, Cascavilla ML, La Morgia C, Triolo G, Giglio R, et al. Macular nerve fibre and ganglion cell layer changes in acute Leber's hereditary optic neuropathy. Br J Ophthalmol. 2016;100(9):1232-7.

11. Barboni P, Savini G, Cascavilla ML, Caporali L, Milesi J, Borrelli E, et al. Early macular retinal ganglion cell loss in dominant optic atrophy: genotypephenotype correlation. Am J Ophthalmol. 2014;158(3):628-36.e3.

12. Altemir I, Pueyo V, Elía N, Polo V, Larrosa JM, Oros D. Reproducibility of optical coherence tomography measurements in children. Am J Ophthalmol. 2013;155(1):171-6.e1.

13. Waldman AT, Hiremath G, Avery RA, Conger A, Pineles SL, Loguidice MJ, et al. Monocular and binocular low-contrast visual acuity and optical coherence tomography in pediatric multiple sclerosis. Mult Scler Relat Disord. 2013;3(3):326-34.

14. Yeh EA, Weinstock-Guttman B, Lincoff N, Reynolds J, Weinstock A, Madurai $\mathrm{N}$, et al. Retinal nerve fiber thickness in inflammatory demyelinating diseases of childhood onset. Mult Scler. 2009;15(7):802-10.

15. Yilmaz Ü, Gücüyener K, Erin DM, Yazar Z, Gürkaș E, Serdaroğlu A, et al. Reduced retinal nerve fiber layer thickness and macular volume in pediatric multiple sclerosis. J Child Neurol. 2012;27(12):1517-23.

16. Avery RA, Rajjoub RD, Trimboli-Heidler C, Waldman AT. Applications of optical coherence tomography in pediatric clinical neuroscience. Neuropediatrics. 2015;46(2):88-97.

17. Lennartsson F, Nilsson M, Flodmark O, Jacobson L. Damage to the immature optic radiation causes severe reduction of the retinal nerve fiber layer, resulting in predictable visual field defects. Invest Ophthalmol Vis Sci. 2014:55(12):8278-88.

18. Jindahra P, Petrie A, Plant GT. Retrograde trans-synaptic retinal ganglion cell loss identified by optical coherence tomography. Brain. 2009;132(Pt 3):628-34.

19. Totan Y, Gürağaç FB, Güler E. Evaluation of the retinal ganglion cell layer thickness in healthy Turkish children. J Glaucoma. 2015;24(5):e103-e8.

20. Gama R, Santos JC, Costa RS, da Costa DC, Eiro N. Optical coherence tomography analysis of the inner retinal layers in children. Can J Ophthalmol. 2018:53(6):614-20.

21. Lee YP, Ju YS, Choi DG. Ganglion cell-inner plexiform layer thickness by swept-source optical coherence tomography in healthy Korean children: normative data and biometric correlations. Sci Rep. 2018;8(1):10605.

22. Pham TT, TN T, Nguyen DT, Mai TD. Macular ganglion cell and retinal nerve fiber layer thickness in normal Vietnamese children measured with optical coherence tomography. Eye South East Asia. 2018;13(1):1-10.

23. Hellgren K, Halberda J, Forsman L, Aden U, Libertus M. Compromised approximate number system acuity in extremely preterm school-aged children. Dev Med Child Neurol. 2013;55(12):1109-14.

24. Serenius F, Ewald U, Faroogi A, Fellman V, Hafstrom M, Hellgren K, et al. Neurodevelopmental outcomes among extremely preterm infants 6.5 years after active perinatal Care in Sweden. JAMA Pediatr. 2016; 170(10):954-63.

25. Huynh SC, Wang XY, Burlutsky G, Mitchell P. Symmetry of optical coherence tomography retinal measurements in young children. Am J Ophthalmol. 2007;143(3):518-20.

26. Chhablani J, Krishnan T, Sethi V, Kozak I. Artifacts in optical coherence tomography. Saudi J Ophthalmol. 2014;28(2):81-7.

27. Baskin DE, Gault JA, Vander JF, Dugan JD Jr. Double fovea artifact. Ophthalmology. 2011;118(2):429.e1.

28. Hyvarinen L, Nasanen R, Laurinen P. New visual acuity test for pre-school children. Acta Ophthalmol. 1980;58(4):507-11. 
29. Serenius F, Kallen K, Blennow M, Ewald U, Fellman V, Holmstrom G, et al Neurodevelopmental outcome in extremely preterm infants at 2.5 years after active perinatal care in Sweden. JAMA. 2013;309(17):1810-20.

30. Satue M, Obis J, Rodrigo MJ, Otin S, Fuertes MI, Vilades E, et al. Optical coherence tomography as a biomarker for diagnosis, progression, and prognosis of neurodegenerative diseases. J Ophthalmol. 2016;2016:8503859.

31. Curcio CA, Allen KA. Topography of ganglion cells in human retina. J Comp Neurol. 1990;300(1):5-25.

32. Molnar A, Holmstrom G, Larsson E. Macular thickness assessed with spectral domain OCT in a population-based study of children: normative data, repeatability and reproducibility and comparison with time domain OCT. Acta Ophthalmol. 2015;93(5):470-5.

33. van Koolwijk LM, Despriet DD, Van Duijn CM, Oostra BA, van Swieten JC, de Koning I, et al. Association of cognitive functioning with retinal nerve fiber layer thickness. Invest Ophthalmol Vis Sci. 2009;50(10):4576-80.

\section{Publisher's Note}

Springer Nature remains neutral with regard to jurisdictional claims in published maps and institutional affiliations.

Ready to submit your research? Choose BMC and benefit from:

- fast, convenient online submission

- thorough peer review by experienced researchers in your field

- rapid publication on acceptance

- support for research data, including large and complex data types

- gold Open Access which fosters wider collaboration and increased citations

- maximum visibility for your research: over $100 \mathrm{M}$ website views per year

At BMC, research is always in progress.

Learn more biomedcentral.com/submissions 